\title{
Histamine and duodenal ulceration in renal transplant recipients
}

\author{
A G TIMONEY, W K MAN, J SPENCER, H TAYLOR, AND G WILliAMS \\ From the Department of Surgery, Royal Postgraduate Medical School, Hammersmith Hospital, London
}

SUMmary Six of 25 renal transplant recipients had a duodenal ulcer at endoscopy. Histamine concentration and the activity of histamine methyltransferase, the degrading enzyme of histamine, were measured in gastric mucosal biopsies obtained at endoscopy and compared with patients with duodenal ulcer but not undergoing transplant and with patients with an apparently normal stomach and duodenum. Histamine concentrations in the corpus (no ulcer, median: $151 \mathrm{nmol} / \mathrm{g}$; DU, median: $122 \mathrm{nmol} / \mathrm{g}$ ) and in the antrum (no ulcer, median: $118 \mathrm{nmol} / \mathrm{g}$; with DU, median: $113 \mathrm{nmol} / \mathrm{g}$ ) of renal transplant patients, irrespective of ulcer diagnosis, and in patients with a chronic duodenal ulcer (median corpus histamine: $137 \mathrm{nmol} / \mathrm{g}$ and median antral histamine: $126 \mathrm{nmol} / \mathrm{g}$ ) were not different from one another but significantly lower than the corresponding values in normal subjects (median corpus histamine: $241 \mathrm{nmol} / \mathrm{g}, \mathrm{p}<0.01$, and median antral histamine: $178 \mathrm{nmol} / \mathrm{g}, \mathrm{p}<0.05$ ). Histamine concentration in the corpus was significantly higher than in the antrum in all three groups of patients $(p<0.05)$. There were no significant differences in histamine methyltransferase activity in any of the groups studied. Mucosal histamine and histamine methyltransferase activity were significantly correlated in the corpus $(p<0.05)$ and antrum $(p<0.02)$. Plasma concentration of histamine after transplant was higher in the patients who subsequently were discovered to have a duodenal ulcer $(p<0 \cdot 05)$. The occurrence of ulcer after transplantation was not related to the serum creatinine level. The uniform depletion of gastric histamine and increase in circulatory histamine after renal transplantation may be a factor in the pathogenesis of duodenal ulcer disease in this clinical situation.

Patients with duodenal ulcer have depleted mucosal histamine stores in the stomach. ${ }^{1}$ This depletion of histamine is associated with gastric hypersecretion, which is a prominent feature of duodenal ulcer disease. After treatment with cimetidine ${ }^{2}$ or vagotomy, ${ }^{3}$ mucosal histamine rises above normal control values, which parallels the reduction in gastric acid secretion. These observations lead to the suggestion that endogenous histamine may reflect the pathogenic states in the gastric mucosa of patients suffering from duodenal ulcer disease. ${ }^{2}$

Renal transplant recipients are known to have an increased risk of developing peptic ulcer, which occurs in $6 \%$ to $22 \%$ of allograft recipients ${ }^{45}$ but the role of $\mathrm{H}_{2}$ receptor blockade in transplant recipients

Address for correspondence: Mr G Williams, FRCS, Department of Surgery. Royal Postgraduate Medical School, London W12 0HS.

Received for publication 29 June 1988 remains controversial. ${ }^{6}$ In a prospective study of 97 consecutive patients undergoing renal transplantation, randomly allocated to prophylactic treatment with placebo or cimetidine, bleeding episodes occurred in 12 patients, 11 of whom were receiving placebo and only one cimetidine.? In another prospective study of 59 patients, however, cimetidine prevented neither gastroduodenal ulceration nor bleeding after renal transplantation. ${ }^{8}$ In the period six months after renal transplantation, nine of 27 cimetidine treated patients and eight of 28 placebo patients developed gastroduodenal erosions or ulcers. ${ }^{8}$

The pathogenesis of peptic ulceration after renal transplantation is unclear. Transplantation may affect gastric secretion. Renal transplant recipients are known to be hypergastrinaemic. ${ }^{9}$ They have been shown to have a higher peak acid output ${ }^{510}$ and basal acid output ${ }^{10}$ than normal controls. Before transplantation peak and basal acid outputs were not different 
from normal control values. ${ }^{5}$ It has also been reported, however, that there were no differences in gastric secretion between patients with chronic renal failure not on dialysis, those on dialysis, or after transplantation. ${ }^{11}$ The aim of the present study was to investigate the possible role of histamine in renal transplant patients with duodenal ulcer disease. We have measured gastric mucosal histamine and its metabolic enzyme, histamine methyltransferase (HMT), as well as circulatory histamine in patients after transplantation.

\section{Methods}

\section{PATIENTS}

In a consecutive series of 25 patients, 12 women, mean age 41 years (range 19-69) and 13 men, mean age 43 years (range $25-65$ ), who had undergone renal transplantation eight to 22 days earlier (mean 13) had oesophago-gastro-duodenoscopy carried out under mild sedation with topical anaesthesia to the oropharynx. The majority of transplants were carried out between 9 am and $9 \mathrm{pm}$. As controls, an unselected consecutive group of 12 patients (four women and eight men, mean age 58 years, range 4366), attending our gastric clinic, in whom endoscopy revealed no visible abnormality were classified as 'normal' controls. Another consecutive series of seven patients (all men, mean age 50 years, range 2673) with duodenal ulcer confirmed at endoscopy were also included in the study.

Six gastric mucosal biopsies, 5-10 mg each, were obtained from each patient using a FB24K Grab forceps. Three were taken from the corpus and three from the antrum; frozen within 30 seconds of closure of the forceps jaw. In seven of 25 patients who had undergone renal transplantation only antral biopsies were obtained by mistake.

Before transplantation 13 patients were maintained on haemodialysis, 10 on peritoneal dialysis, and two were not dialysis dependent. Twenty four patients were on a triple therapy immunosuppressive regime of cyclosporin $\mathrm{A}, 10 \mathrm{mg} / \mathrm{kg}$ daily orally; azathioprine, $5 \mathrm{mg} / \mathrm{kg}$ intravenously perioperatively and thereafter $1 \mathrm{mg} / \mathrm{kg}$ daily orally from day two. Steroids given routinely were methylprednisolone $1 \mathrm{~g}$ intravenously perioperatively, hydrocortisone 100 $\mathrm{mg}$ bd until postoperative ileus had resolved and thereafter prednisolone $20 \mathrm{mg}$ daily. The remaining patient, from abroad, was on oral steroids and azathioprine.

Blood was taken for plasma histamine estimation in 12 patients after transplantation. The intraoperative samples and the samples taken during the first 24 hours postoperatively were taken from a central venous cannula. The basal samples and the daily samples, reserved at 8 am were taken by peripheral venous puncture. Blood samples were also collected for routine serum creatinine assay.

\section{GASTRIC HISTAMINE ASSAY}

Each biopsy was homogenised separately in $0.5 \mathrm{ml}$ ice cold $0.01 \mathrm{M}$ sodium phosphate buffer, $\mathrm{pH} 6.5$, containing $0.1 \%(w / v)$ Triton $X-100$. The homogeniser was washed through with three portions of $0.5 \mathrm{ml}$ cold buffer. One millilitre of the homogenate was assayed for histamine, $80 \mu \mathrm{l}$ for HMT assay and $50 \mu \mathrm{l}$ in duplicate for protein assay by the method of Lowry et al. ${ }^{12}$

The assay procedures for histamine have been described in detail previously and involved the selective extraction of histamine in the homogenate by passing through a short column of Dowex $50 \mathrm{~W}-\mathrm{X} 8$ ion exchange resin. ${ }^{2}$ Results were expressed as the mean values in $\mathrm{nmol} / \mathrm{g}$ tissue of the three biopsies obtained in each region of the stomach.

\section{GASTRIC HISTAMINE METHYLTRANSFERASE (HMT) ASSAY}

The assay procedures for histamine methyltransferase activity have been described in detail. ${ }^{13}$ Results were expressed in pmol $\mathrm{N}$-methyl histamine formed per milligram protein per minute incubation.

\section{PLASMA HISTAMINE ASSAY}

Histamine was assayed by a modification of the enzymatic isotopic method. ${ }^{14}$ Plasma histamine was assayed in duplicate samples and the mean values were expressed in $\mathrm{nmol} / \mathrm{l}$.

\section{STATISTICAL ANALYSIS}

Statistical comparisons were made using MannWhitney U test, Wilcoxon's match-pairs signed-rank test, Kruskall-Wallis one way analysis of variance and Spearman rank correlation. $p$ Values less than 0.05 were accepted as significant.

\section{Results}

DUODENAL ULCER IN RENAL TRANSPLANT RECIPIENTS

Six of 25 renal transplant recipients had a duodenal ulcer diagnosed at endoscopy. Two patients had endoscopic duodenitis. Of the remaining 17 patients, gastroduodenoscopy revealed no visible abnormality. As these patients had not previously been endoscoped, it is not known whether they had ulcers before transplantation.

MUCOSAL HISTAMINE AND HISTAMINE

METHYLTRANSFERASE ACTIVITY

Figure 1 shows the mucosal histamine values in 


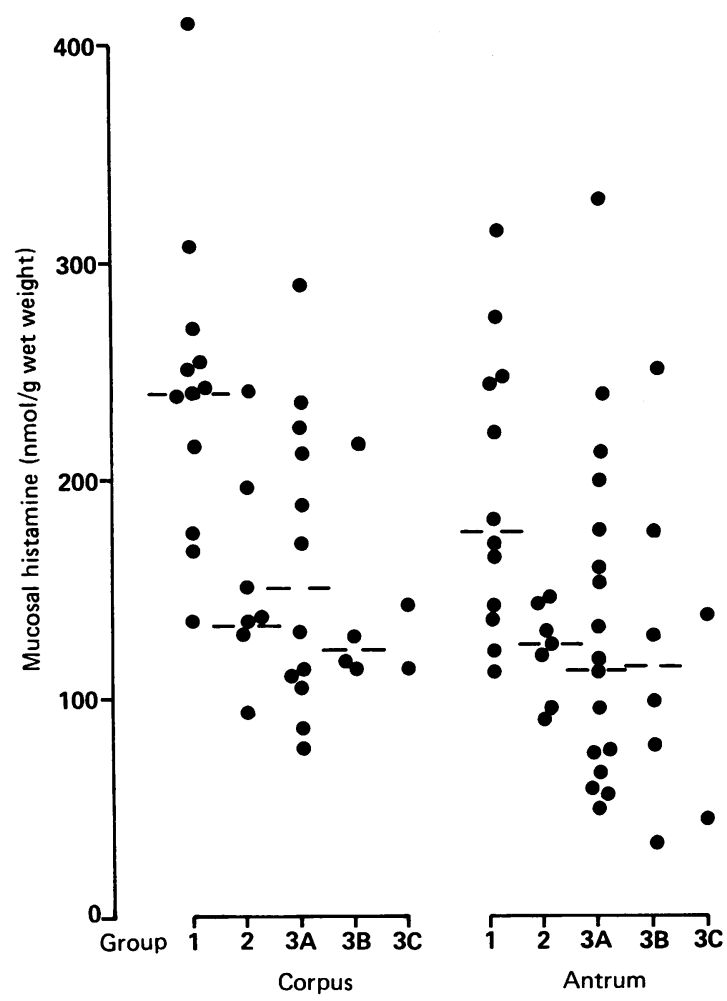

Fig. 1 Mucosal histamine concentration in corpus and antrum. Group 1: 'normal' subjects; group 2: patients with duodenal ulcer but not having renal transplantation; group 3A: transplantation recipients with no ulcer seen at endoscopy; group $3 B$ : with duodenal ulcer; group $3 C$ : with duodenitis. (- -): median.

'normal' subjects (group 1), ulcer patients (DU, group 2) and the renal transplant patients (group 3). Group 3 was subclassified as 3A: 'no ulcer' (RTNU), 3B: 'ulcer' (RTDU), and 3C: 'duodenitis' according to endoscopic diagnosis. In the corpus the median 'normal' histamine value was $241 \mathrm{nmol} / \mathrm{g}$ wet weight of the biopsy. All other groups had significantly lower values (analysis of variance, $\mathrm{H}=12.70, \mathrm{p}<0.01$ ). Duodenal ulcer median corpus histamine was $43 \%$ lower than in 'normal' controls $(p<0 \cdot 01)$. The median corpus histamine value in the 12 RTNU patients was $37 \%$ lower than in 'normal' $(p<0 \cdot 01)$. In the four RTDU patients the median histamine value was $49 \%$ lower than in 'normal' subjects $(\mathrm{p}<0 \cdot 01)$. There was no significant difference between the median histamine values in DU and RTNU or RTDU.

The median antral histamine in 'normal' subjects was higher than in other groups. This difference was not statistically significant on analysis of variance

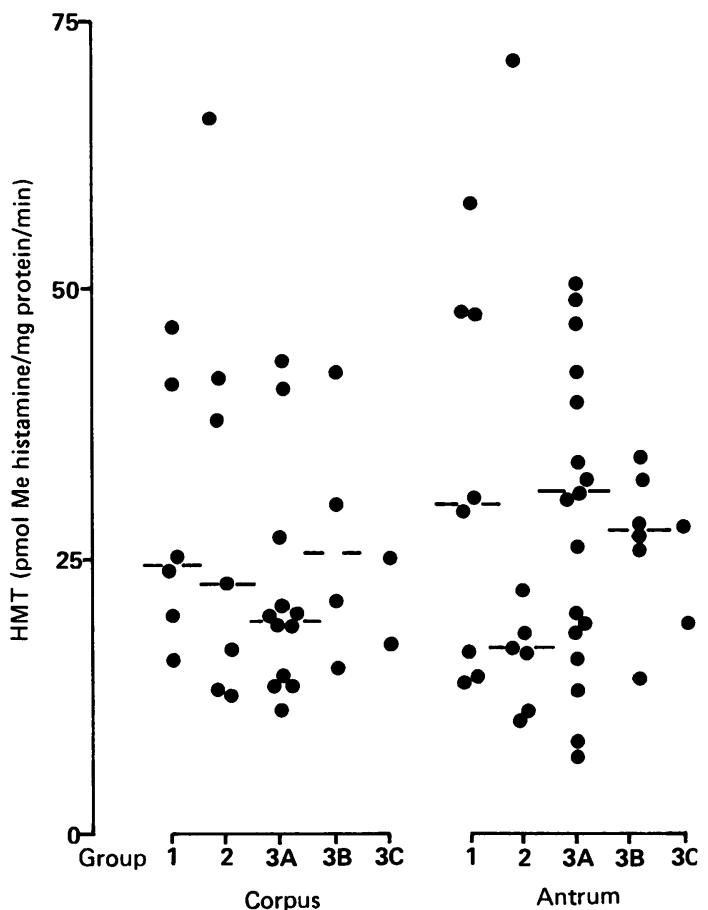

Fig. 2 Mucosal histamine methyltransferase (HMT) activity in corpus and antrum. Symbols used as in Fig. 1.

( $\mathrm{H}=8 \cdot 37$, NS). Nevertheless, comparisons between individual groups show that the antral histamine in DU patients was significantly lower than in normal $(p<0.05)$; as was that of RTNU; $p<0.025)$ and RTDU; $p<0.05)$. No significant difference in antral histamine values was found between DU, and the transplant groups.

In 'normal' histamine concentrations in corpus were significantly higher than those in antrum (Wilcoxon's test, $\mathrm{p}<0.05$ ). Similarly, in DU and in RTNU corpus histamine concentrations were significantly higher than antral histamine values $(\mathrm{p}<0.05$, respectively).

Figure 2 shows the activity of histamine methyltransferase (HMT) in corpus and antral biopsies. No significant differences were observed in any of the groups studied.

Figure 3 shows a significant correlation between mucosal histamine and HMT activity in both the corpus $(\mathrm{p}<0.05)$ and antrum $(\mathrm{p}<0.02)$.

\section{PLASMA HISTAMINE CONCENTRATION AFTER}

RENAL TRANS PLANT

Blood samples were collected before renal transplantation and on each of 12 days after operation. Plasma histamine concentrations were assayed in seven 




Fig. 3 Correlation between gastric mucosal histamine concentration and HMT activity in the corpus and antrum. Corpus: $r_{\mathrm{s}}=0 \cdot 36, p=0 \cdot 046, n=31(\mathrm{O})$; regression line (----); Antrum: $r_{\mathrm{s}}=0.39, p=0.015, n=39(\mathrm{O})$; regression line (-); Overall: $r_{\mathrm{s}}=0 \cdot 36, p=0 \cdot 002, n=70$.

patients with no visible abnormality in the duodenum and five patients with duodenal ulcer disease. The histamine values are listed in the Table.

No significant difference was found between the two groups, although those patients that developed ulcer tended to have higher plasma histamine in the recovery period, particularly in the first four days after surgery.

Figure 4 shows the highest plasma histamine value assayed in each patient in the recovery period from day 1 after surgery. Before transplant the basal

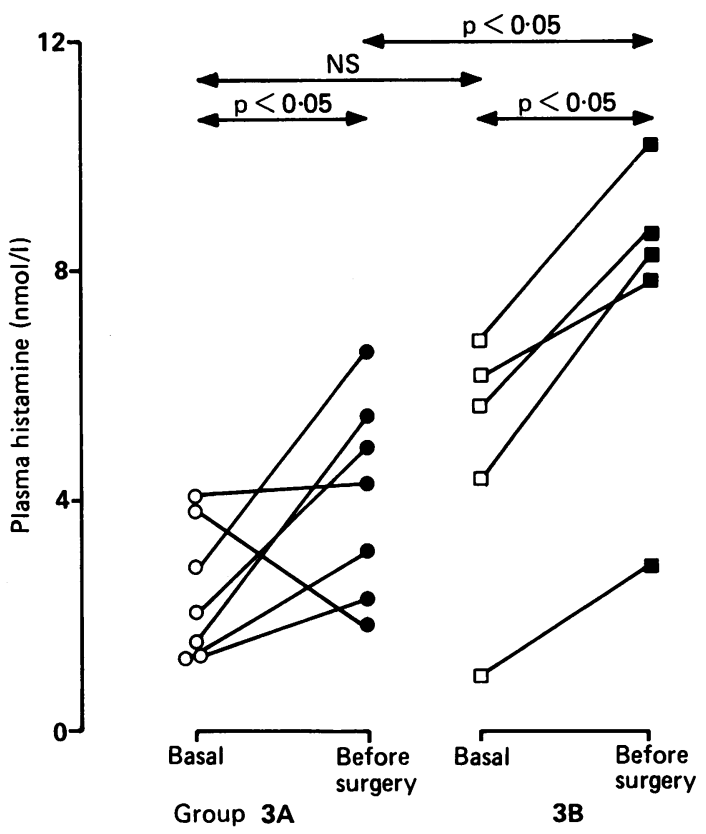

Fig. 4 Plasma histamine concentrations before and after renal transplantation. $(\mathrm{O})$ basal and $(1)$ highest assayed values in transplant patients with no ulcer. (ㅁ) respectively in patients with duodenal ulcer.

plasma histamine concentration values were not significantly different between the two groups of patients. After surgery plasma histamine rose

Table Plasma histamine and serum creatinine in patients after renal transplant

\begin{tabular}{|c|c|c|c|c|c|c|c|c|c|c|}
\hline & \multicolumn{5}{|c|}{ Patients developed $D U$} & \multicolumn{5}{|l|}{ No $D U$} \\
\hline & \multicolumn{2}{|c|}{ Histamine (nmolll) } & \multicolumn{2}{|c|}{ Creatinine ( $\mu$ molll) } & \multirow[b]{2}{*}{$n$} & \multicolumn{2}{|c|}{ Histamine (nmolll) } & \multicolumn{2}{|c|}{ Creatinine ( $\mu \mathrm{mol} / \mathrm{l})$} & \multirow[b]{2}{*}{$n$} \\
\hline & Median & Range & Median & Range & & Median & Range & Median & Range & \\
\hline Basal & $5 \cdot 58$ & $0.91-6.7$ & 617 & $310-1144$ & 5 & 2.03 & $1.25-3.98$ & 858 & $540-1100$ & 7 \\
\hline Induction & $5 \cdot 57$ & $3.03-8.47$ & & & 4 & 5.95 & $1.45-10.05$ & & & 7 \\
\hline Surg $30^{\prime}$ & $5 \cdot 27$ & $0.64-9.43$ & & & 5 & $6 \cdot 14$ & $1.48-7.85$ & & & 7 \\
\hline $1 \mathrm{~h}$ & $4 \cdot 59$ & $0 \cdot 54-13 \cdot 51$ & & & 5 & $5 \cdot 51$ & $0.90-12 \cdot 41$ & & & 6 \\
\hline $2 \mathrm{~h}$ & 3.45 & $0 \cdot 32-9 \cdot 36$ & & & 4 & $8 \cdot 11$ & $2 \cdot 41-12 \cdot 18$ & & & 7 \\
\hline $4 h$ & $12 \cdot 04$ & $10 \cdot 02-20 \cdot 87$ & & & 4 & 6.45 & $2 \cdot 52-18 \cdot 45$ & & & 4 \\
\hline $8 \mathrm{~h}$ & $7 \cdot 36$ & $0.84-7.60$ & & & 3 & $5 \cdot 14$ & $2 \cdot 09-12 \cdot 60$ & & & 4 \\
\hline \multicolumn{11}{|l|}{ Recovery } \\
\hline Day 1 & $7 \cdot 61$ & $6 \cdot 14-8 \cdot 62$ & 407 & $300-785$ & 3 & $2 \cdot 74$ & $1.49-6 \cdot 38$ & 770 & $265-930$ & 6 \\
\hline 2 & $5 \cdot 78$ & $1 \cdot 20-10 \cdot 23$ & 455 & $155-885$ & 4 & 2.96 & $0.71-5.02$ & 487 & $116-950$ & 7 \\
\hline 3 & $5 \cdot 68$ & $0.78-8.09$ & 250 & $128-870$ & 4 & 1.67 & $0.79-3.41$ & 523 & $116-1075$ & 6 \\
\hline 4 & $4 \cdot 33$ & $3.94-4.48$ & 310 & $282-990$ & 3 & $2 \cdot 18$ & $0.46-6.58$ & 152 & $125-661$ & 5 \\
\hline 5 & $2 \cdot 80$ & $1.34-4.46$ & 247 & $180-575$ & 3 & $2 \cdot 34$ & $1.40-5.98$ & 362 & $122-900$ & 7 \\
\hline 6 & $4 \cdot 87$ & $0.53-7.86$ & 462 & $175-900$ & 4 & 2.04 & $1 \cdot 35-6 \cdot 14$ & 301 & $150-853$ & 7 \\
\hline 7 & $2 \cdot 21$ & $1 \cdot 30-10 \cdot 14$ & 575 & $270-1075$ & 5 & $1 \cdot 50$ & $0.63-3 \cdot 40$ & 250 & $200-735$ & 5 \\
\hline 8 & 3.65 & $1 \cdot 13-10 \cdot 42$ & 650 & $360-1019$ & 5 & 1.55 & $0.63-3.36$ & 361 & $175-925$ & 6 \\
\hline 9 & $3 \cdot 55$ & $0 \cdot 83-7 \cdot 20$ & 535 & $345-832$ & 3 & $2 \cdot 84$ & $1 \cdot 12-6 \cdot 14$ & 302 & $157-950$ & 4 \\
\hline 10 & $5 \cdot 61$ & $1.40-9.25$ & 625 & $447-955$ & 4 & $2 \cdot 54$ & $1.14-3.65$ & 292 & $150-735$ & 7 \\
\hline 11 & $2 \cdot 86$ & $1 \cdot 37-4 \cdot 35$ & 477 & $434-520$ & 2 & $2 \cdot 55$ & $1 \cdot 17-3 \cdot 26$ & 260 & $165-900$ & 4 \\
\hline 12 & 1.86 & $0.81-2.90$ & 512 & $390-635$ & 2 & $3 \cdot 15$ & $1.43-5.77$ & 330 & $168-700$ & 4 \\
\hline
\end{tabular}




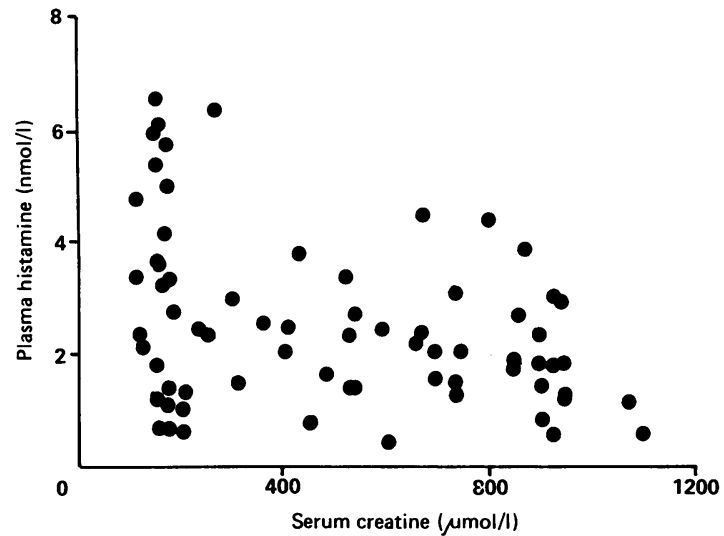

Fig. 5 Correlation between plasma histamine and serum creatinine in transplant recipients with no ulcer. $r_{\mathrm{s}}=-0 \cdot 35$, $p<0.005, n=72$.

significantly in both groups $(p<0.05$, Wilcoxon's test). Those patients with duodenal ulcer had significantly higher plasma histamine concentration than those with no ulcer $(p<0 \cdot 05$, Mann-Whitney $U$ test $)$.

\section{SERUM CREATININE AND HISTAMINE}

On endoscopy day, serum creatinine concentration in transplant recipients who later showed no ulcer (median: 260, range: $130-900 \mu \mathrm{mol} / / \mathrm{n}=17$ ) was not significantly different from recipients with an ulcer (median: 585 , range: $345-1080, n=6$ ). No significant correlation was observed between serum creatinine and gastric histamine nor HMT in the two groups of transplant patients.

For the 12 patients in whom plasma histamine was also studied, the corresponding serum creatinine

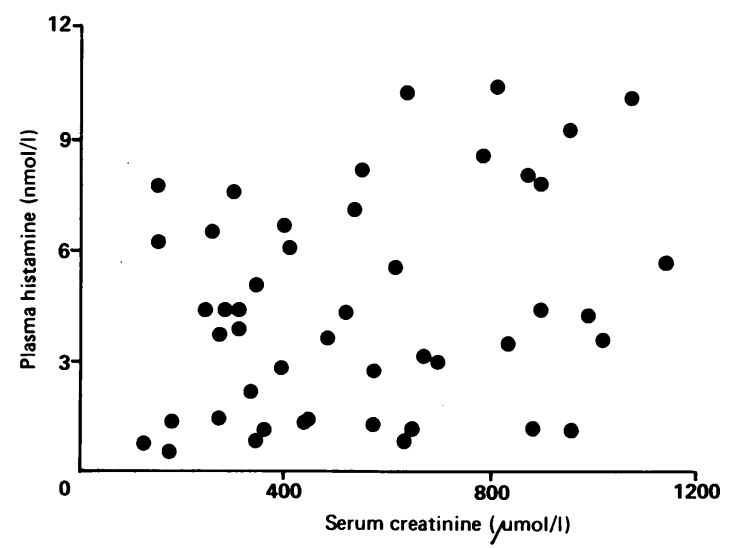

Fig. 6 Correlation between plasma histamine and serum creatinine in transplant recipients with $D U . R_{\mathrm{s}}=0 \cdot 20$, $p=0 \cdot 17, N S, n=47$. values are listed in the Table. A significant negative correlation between serum creatinine and plasma histamine was observed in the seven no-ulcer patients $(p<0.005)$ (Fig. 5). No correlation was found in the five transplant patients who later showed an ulcer (Fig. 6).

\section{Discussion}

Low gastric mucosal histamine has been previously described in patients with duodenal ulcer, ${ }^{2.315}$ and this finding has been confirmed in the present study. We have now noted the same phenomenon in patients after renal transplantation.

Lorenz et al have recently reported on the methods for the assay of histamine in endoscopic biopsy specimens. ${ }^{16}$ In order to obtain accurate and reproducible results a strict protocol in the assay procedures must be followed. They recommended a modified Shore's method as superior to the ion exchange procedures for extraction of histamine employed in this study.

In our laboratory we have also used a rigid routine in the histamine assay. In the present study, the corpus histamine concentrations in normal subjects (median $241 \mathrm{nmol} / \mathrm{g}$, range: $135-410, \mathrm{n}=12$ ) is consistent with the results reported in the past (median $204 \mathrm{nmol} / \mathrm{g}$, range: $127-540, \mathrm{n}=25 ;{ }^{9}$ and, median 252 nmol/g, range: 202 to $\left.457, n=10,{ }^{10}\right)$. In the three studies the median values for duodenal ulcer patients were $43 \%, 22 \%$, and $19 \%$ lower than in controls respectively. These values were comparable to the average findings reported by the Marburg group of investigators. ${ }^{16}$

In the present study we have found that the gastric mucosal histamine content in corpus and antrum is significantly lower in renal transplant patients, with or without an ulcer, than in normal controls. The magnitude of these reductions is similar to that seen in patients with chronic duodenal ulcer, ${ }^{17}$ in whom, as in our patients, the reduction is not specific for the acid producing stomach but is also present in the gastric antrum.

In the stomach mucosal histamine concentration is significantly higher in the corpus than in the antrum of normal controls, duodenal ulcer patients and renal transplant patients without an ulcer. This comparative abundance of histamine in the corpus has been postulated to play a vital role in the mediation of gastric acid secretion. ${ }^{18}$ No such difference was found in the transplant patients with a duodenal ulcer but this may well be because of the small sample size.

No significant differences in the methyltransferase activity were observed in the corpus or antrum of any of the groups studied. This contrasts with a study by Barth et al, who in a study of 15 patients and 18 
controls found significantly lower levels of HMT activity in the duodenal ulcer groups. ${ }^{19}$ Another report, of 79 patients and 62 controls, found significantly reduced HMT activity in the fundus of ulcer patients, ${ }^{15}$ and a positive correlation between mucosal histamine and HMT activity in men with duodenal ulcer. In the present study we also found a significant correlation between mucosal histamine and HMT activity. The significance of alterations in HMT activity in gastric mucosa remains unclear.

In the present study all renal transplant recipients were given steroid therapy exceeding one gram of methylprednisolone, a dosage that may cause peptic ulceration..$^{20}$ The amount of steroid received by patients who were subsequently found to have a duodenal ulcer, however, was not higher than that taken by patients who did not develop ulcer.

After transplantation serum creatinine concentration in patients who had ulcer was not significantly different from that in patients without an ulcer but the former tended to be higher. No correlation was observed between gastric histamine and serum creatinine. As patients in chronic renal failure or after transplantation are known to be hypergastrinaemic ${ }^{9}$ and gastrin may act by mobilising histamine,$^{21}$ the three factors: renal function, circulatory gastrin, and gastric histamine metabolism in transplant recipients are currently under investigation.

The finding of reduced mucosal histamine in renal transplant patients with and without ulcer may indicate that histamine is not the sole factor in the pathogenesis of the disease. Depletion of the endogenous store, however, may be the first step in the aetiology of duodenal ulcer disease, invoking other pathogenic factors for the breaking of the mucosal barrier. ${ }^{22}$ Twenty four per cent of our patients were found to have a duodenal ulcer after transplantation in this study.

Indeed, in a small group of transplant patients, in the first few days after surgery, histamine concentration rose, and more so in those that subsequently developed ulcer. This suggests augmented histamine release though the source of release was not ascertained in this study. Alternatively the raised plasma histamine may be related to the daily administration of cylosporin A or steroids. This rise in plasma histamine concentration after transplantation was not seen in the earlier study by Lorenz and Doenicke. $^{23}$ It is not known whether plasma histamine rises after other major operations.

The kidney is the main organ involved in the removal of excessive histamine in circulation by excretion and by inactivation as renal tissue is rich in the inactivating enzyme, HMT. ${ }^{17}$ In the present study, it is interesting that only in those recipients without duodenal ulcer circulatory histamine is inversely related to renal function as monitored by serum creatinine level. Further experiments are in progress to relate renal failure and circulatory histamine to the occurrence of duodenal ulcer.

We thank $\mathrm{Mr}$ Kang $\mathrm{Li}$ for his skilled technical assistance.

\section{References}

1 Troidl H, Lorenz W, Rohde H, et al. Histamine and peptic ulcer: a prospective study of mucosal histamine concentration in duodenal ulcer patients and in control subjects suffering from various gastrointestinal diseases. Klin Wochenschr 1976; 54: 947-56.

2 Man WK, Saunders JH, Ingoldby C, Spencer J. Effect of cimetidine on the amounts of histamine in the gastric mucosa of patients with duodenal or gastric ulcers. Gut 1981; 22: 923-6.

3 Troidl H, Rohde H, Lorenz W, Hafner G, Hamelmann $\mathrm{H}$. Effect of selective gastric vagotomy on histamine concentration on gastric mucosa of patients with duodenal ulcer. Br J Surg 1978; 65: $10-6$.

4 Sarodsy MF, Cruz AB, Saylor R, Gaskill HV, Dittman W, Banowsky LH. Upper gastrointestinal bleeding following renal transplantation. Urology 1985; 26: 34750.

5 Chisholm GD, Mee AD, Williams G, Castro JE, Baron JH. Peptic ulceration, gastric secretion and renal transplantation. Br Med J 1977; 1: 1630-3.

6 Doherty CC. Effect of cimetidine on upper gastrointestinal bleeding after renal transplantation [Letter]. Br Med J 1984; 289: 1539-40.

7 Walter S, Thorup Anderson J, Christensen U, et al. Effect of cimetidine on upper gastrointestinal bleeding after renal transplantation: a prospective study. $\mathrm{Br}$ Med J 1984; 289: 1175-6.

8 Schiessel R, Starlinger M, Wolf A, et al. Failure of cimetidine to prevent gastroduodenal ulceration and bleeding after transplantation. Surgery 1981; 90: 456-8.

9 El Ghonaimy E, Barsoun R, Soliman M, et al. Serum gastrin in chronic renal failure: morphological and physiological considerations. Nephron 1985; 39: 86-94.

10 Doherty CC. Gastric secretion in chronic uraemia and after renal transplantation. Ir J Med Sci 1980; 149: 5-9.

11 Paimela H, Harkonen H, Karonen S-L, Tallgren LG, Ahonen $\mathbf{J}$. The effect of renal transplantation of gastric acid secretion and on serum levels of gastrin and group pepsinogens. Ann Clin Res 1983; 17: 105-9.

12 Lowry OH, Rosebrough NJ, Farr AL. Protein measurement with the Folin phenol reagent. J Biol Chem 1951; 127: $182-6$.

13 Man WK, Thompson JM, Baron JH, Spencer J. Histamine and duodenal ulcer: effect of omeprazole on gastric histamine in patients with duodenal ulcer. Gut 1986; 27: 418-22.

14 Beaven MA, Aiken DL, Woldemussie E, Soll AH. Changes in histamine synthetic activity, histamine content and responsiveness to compound 48/80 with maturation of rat peritoneal mast cells. J Pharmacol Exp Ther 1983; 224: 620-5. 
15 Peden NR, Callachan H, Shepherd DM, Wormsley KG. Gastric mucosal histamine and histamine methyltransferase in patients with duodenal ulcer. Gut 1882 ; 23: 5862.

16 Lorenz W, Thon K, Neugebauer E, et al. Reliability and practicability of the fluorometric-fluoroenzymatic histamine determination in pathogẹnetic studies on peptic ulcer: Detection limits and problems with specificity. Agents Actions 1987; 21 : 1-25.

17 Thon KP, Lorenz W, Ohmann CH, Weber D, Rohde H, Roher HD. Sample taking problems in measuring actual histamine levels in human gastroduodenal mucosa: specific and general relevance in clinical trials on peptic ulcer pathogenesis and selective proximal vagotomy. Gut 1985; 26: 1165-78.

18 Lorenz W, Thon K, Barth H, Neugebauer E, Reimann $\mathrm{HJ}$, Kuche J. Metabolism and function of gastric histamine in health and disease. J Clin Gastroenterol 1983; 5 [suppl 1]: 37-56.
19 Barth H, Troidl H, Lorenz W, Rohde H, Glass R. Histamine and peptic ulcer disease: histamine methyltransferase activity in gastric mucosa of control subjects and duodenal ulcer patients before and after surgical treatment. Agents Actions 1977; 7: 75-9.

20 Conn HO, Blitzer BL. Medical progress: Nonassociation of adrenocorticosteroid therapy and peptic ulcer. N Engl J Med 1976; 294: 473-9.

21 Man WK, Ingoldby CJH, Spencer J. Is pentagastrinstimulated secretion mediated by histamine? Gut 1984; 25: 965-70.

22 Venables CW. Mucus, pepsin and peptic ulceration. Gut 1986; 27 : 233-8.

23 Lorenz W, Doenicke A. $\mathrm{H}_{1}$ and $\mathrm{H}_{2}$ blockade: a prophylactic principle in anaesthesia and surgery against histamine-release responses of any degree of severity: part 1. NER Allergy Proc 1985; 6: 37-57. 